IOS Press

\title{
Age of entry into the labor market and career success: The case of the NFL
}

\author{
Jun Woo Kim* \\ Arcadia University, Easton Road, Glenside, PA, USA
}

\begin{abstract}
The consensus across labor market research in sports and non-sports literature has shown that there is a significant interaction between age, ability, and performance. While this relationship is at the foundation of all acts of production or utility creation, little econometric work exploring the role of precocity in career success can be found in the literature. This study therefore examines the role of precocity on labor market outcomes of elite-level National Football League (NFL) players and, indirectly, assesses the on-field efficacy of the NFL's age rule. The findings indicate that precocity, as measured by the age of entry into the elite-level professional football labor pool, leads to better career success. That is, the younger a player is when he first enters the NFL labor market; the more successful he is likely to be.
\end{abstract}

Keywords: NFL, career success, age eligibility rule, antitrust law

\section{Introduction}

This study extends previous research that examines the relationship between age of entry into the sports labor pool and career success (e.g., Rodenberg \& Kim, 2012; Rodenberg \& Stone, 2011; Sowell \& Mounts, 2005) by investigating the impact of precocity on career-level performance of National Football League (NFL) players. The NFL has faced several legal issues since its inception, with one of the most prominent being the age eligibility rule. Prior to 1990, college football players were only allowed to enter the NFL draft after the completion of four seasons. When Paul Tagliabue, the new commissioner of the NFL, took over in 1989 he was praised as a player's commissioner, as no strikes or lockouts occurred under his tenure. One of the first major policy changes Tagliabue made pertained to the age eligibility rule of collegiate athletes seeking to enter the NFL draft. Tagliabue's new rule allowed any college football player, three years

*Corresponding author: Jun Woo Kim, Arcadia University, $450 \mathrm{~S}$. Easton Road, Glenside, PA 19038, USA. Tel.: +1 267620 47700; Fax: +1 215572 4489; E-mail: kimjw@ arcadia.edu. removed from high school, the ability to enter the 1990 draft (McCann \& Rosen, 2006).

Since the implementation of this rule change, however, there have been many athletes who have attempted to challenge the NFL over this issue and gain earlier entrance than the mandated three year time period. A few examples of athletes who have sought permission to enter the NFL draft earlier than permitted by the age eligibility rule are Eric Swann, Larry Fitzgerald, and Maurice Clarett (Edelman \& Wacker, 2010). In September 2003, Ohio State sophomore running back Maurice Clarett filed an antitrust lawsuit against the NFL club-owners upon learning of his rejection for the NFL draft before his threeyear anniversary of his high school graduation (i.e., Clarett vs. NFL, 2004). Clarett, who had grown up in a financially hard-pressed family, had impressive football credentials when he petitioned the NFL for early entry into the 2004 draft. As a freshman, he led his team to their first national championship in 34 years, and was named by The Sporting News as the nation's top college football running back (McCann \& Rosen, 2006). The U.S. District Court for the Southern District of New York ruled in plaintiff Clarett's favor, declaring that 
the NFL's age eligibility rule was subject to antitrust scrutiny. The NFL, however, appealed to the United States Second Circuit Court of Appeals, and the decision was reversed and held that the NFL's age eligibility rule warranted protection from antitrust scrutiny by the non-statutory labor exemption. A non-statutory labor exemption frequently applies to the context of a sports leagues' collectively bargained age requirement. Edelman and Wacker (2010) argue that the non-statutory labor exemption shields from antitrust scrutiny any conduct that "is reached through the proper workings of the collective bargaining relationship.' (p. 365). Thus, the non-statutory labor exemption is designed to protect sports associations, allowing associations to collectively bargain without fear of reprisal for collusive behavior in which labor law, rather than antitrust law, is applied to situations where collective bargaining occurs. Upon the Second Circuit decision in Clarett vs. NFL, in 2006, the NFL's age eligibility rule was formally moved into their collective bargaining agreement.

Unlike other sports leagues such as Major League Baseball (MLB), NASCAR, professional tennis, the National Hockey League (NHL), and professional golf, the NFL and the National Basketball Association (NBA) are the only major sports banning players from draft until a prescribed period after high school graduation. Currently the NFL age eligibility rule is premised on four main beliefs that deny a player the right to enter the NFL draft early: (a) they cannot meet the mental and physical demands of the NFL, (b) the risk of injury has significantly increased, (c) they would tarnish the image of the NFL and turn fans away, and (d) younger players may be more likely to engage in illegal acts such as steroid use in order to keep up with the demands of the sport (McCann \& Rosen, 2006). From a labor law perspective, Edelman and Wacker (2011) alleged that a sports union's agreement to a collectively bargained age eligibility rule violates the „,duty of fair representation' when the union represents prospective draftees into a sports league. By denying talented players from entering the NFL, the prospective players would be considered victims of discrimination as the result of their lack of voting power in the players union and a rule that eliminates them from working despite having adequate skill.

With ample ethical and legal controversy swirling, this study aims to analyze the relationship between age of entry into the professional football labor pool and career success. Specifically, this study examines the role of precocity on labor market outcomes of elite-level NFL players and, indirectly, tests the onfield efficacy of the NFL's age rule. In the context of sports labor markets, precocity has been defined as a player's physical ability or talent that reaches to his or her peak performance at a relatively young age (Helsen, Hodges, Winckel, \& Starkes, 2000). In this study, precocity is measured by the age of entry into the elite-level professional football labor pool. The use of the phrase "on-field" is consciously made, as the aim here is to emphasize the "during game" football performance, not off-field issues such as "the value of higher education, purported socially irresponsible behavior or criminal activity, and the pecuniary aspects of being a professional athlete" (Rodenberg \& Kim, 2012, p.1).

This study relates to the previous research on using sports industry data to test economic hypotheses (e.g., Kahn, 2000; Rosen \& Sanderson, 2001). An important factor that determines the labor supply of professional teams is the need to develop athletes' natural talents at very young ages (Rosen \& Sanderson, 2001). Many studies have examined aging and players' peak performance in sports (Schulz \& Curnow, 1988; Fried \& Tauer, 2011). For example, Sowell and Mounts (2005) examined the interaction between age and ability, postulating that "ability or talent, particularly physical ability, is inherent to the individual largely beyond choice... the relationship between age, ability, and performance is one of the most basic in all of economics' (p. 79). Specific to the topic of precocity and labor market outcomes in the sports, Rodenberg and Stone (2011) tested the effect of minimum age rule by comparing female professional tennis player career outcomes before and after a minimum age rule was adopted. The results of the study showed that the age rule has very limited impact on players' career success.

Specific to the NFL, playing careers have been investigated vis-à-vis returns to college education (Böheim \& Lackner, 2012), the influence of off-field conduct (Stair, Day, Mizak, \& Neral, 2008), round of draft pick (Hendricks, Debrock, \& Koenker, 2003), and managerial life cycle (Goff \& Wisley, 2006). Such emerging research has consistently pointed out that labor supply in the NFL is determined by one's natural talents, attitude toward risk and precocity. As a result, there is a relationship between precocity and career success, and this connection is recognized as a low-cost proxy for a type of player performance. This study sheds light on whether the age of entry into the labor market impacts career-level performance. 


\section{Data and analytical framework}

Data were collected from two publicly available sources: Pro-Football-Reference.com and the official website of NFL.com. The data set comprises all NFL first round draft picks from 1975-2005, a total of 896 observations. While the NFL's annual draft is comprised of seven rounds in reverse-order based on overall record the previous year, apart from any trades, focus on the first round is for practical reasons. Career and biographical data for obscure players drafted in later rounds were not available. The sample is bifurcated in two distinct ways to account for censored data (69 out of the 896 players in a full sample were active during the 2013 NFL season) and highlight year effects in the spirit of a regression discontinuity design. The 31 year period with 1990 as a mid-point was important to the study design given that in 1990 , for the first time in league history, the NFL reduced its age requirement by one year.

The Estimating equation included the following player-level independent variables: age of NFL entry $(A G E)^{1}$, weight $(W T)$, and ordinal data pertaining to draft pick slot (DRFT), which indicates a relative ranking and is a reasonable proxy for talent. The following time-constant dummy variables were also included in the estimation: playing position $(P S T N)^{2}$, college graduate $(C L L G E)^{3}$, race $(R A C E)^{4}$, and rule change (RULECHNG $)^{5}$. The variable of interest was $A G E$. To test the research hypothesis that age of entry has an effect on NFL career, I adopted the following multiple dependent variables, as there is no consensus measure of NFL career success: ${ }^{6}$ weighted career approximate value $(C A R A V)^{7}$, length of NFL career in years $(C R Y R)^{8}$, years as primary starter $(Y R P S)$, and all-pro selection $(A P S)$. Dependent variables were modeled

\footnotetext{
${ }^{1}$ Entry age is calculated as the difference between the year of draft and the year of birth to eliminate variation that is caused by the seasonality of hiring (Böheim \& Lackner, 2012).

${ }^{2}$ Quarterback or non-quarterback.

${ }^{3}$ College graduate or non-college graduate.

${ }^{4}$ Black or nonblack.

${ }^{5}$ Draftees before the rule change or after the rule change (1990 as an equalizing fulcrum for our 31 year sample).

${ }^{6}$ Salary was not included as dependent variable because there are nonmonetary reasons why players enter into a contract with a certain team during free agency (McCann \& Rosen, 2006).

${ }^{7}$ For a full description regarding the calculation of CARAV, see Pro-Football-Reference.com.

${ }^{8}$ The number of seasons a player completed in the NFL. CRYR is included to test the impact of any human capital accumulation.
}

using a censored normal regression estimator because a small number of the players are still active in the NFL. Consistent with a natural experimental approach, I included a dummy variable that halves a full sample: 1975-1989 (sub-sample \#1 before the rule change) and 1990-2005 (sub-sample \#2 after the rule change). Using 1990 as an equalizing fulcrum for the 31 year sample is intuitive and practical. Descriptive statistics of variables are set forth in Table 1.

The general form estimating equation is as follows:

$$
\begin{aligned}
Y_{i}= & \beta_{0}+\beta_{1} A G E_{i}+\beta_{2} W T_{i}+\beta_{3} D R F T_{i} \\
& +\beta_{4} P_{S T N}+\beta_{5} C L L G E_{i}+\beta_{6} R A C E_{i} \\
& +\beta_{7} R U L E C H N G_{i}+\varepsilon_{i}
\end{aligned}
$$

with $Y_{\mathrm{i}}$ denoting the career outcome dependent variables such as $C A R A V, C R Y R, Y R P S$, and APS. Along with a variable of interest $(A G E)$, control variables are consistent with many of those used in the general economics literature pertaining to human capital accumulation (e.g., Acemoglu, 1996; Rosen, 1983) and the relevant sports economic literature (e.g., Staw \& Hoang, 1995).

\section{Results}

Across each of the four dependent variables (CARAV, CRYR, YRPS, and APS), I found that players who enter the NFL at a relatively younger age are more likely to have successful on-field careers (see Table 2). The importance of such precocity, as evidenced by a negative coefficient for the AGE variable, is consistent across all four specifications. For every year older a player is when he enters the NFL, it is expected that he will: (i) earn a $C A R A V$ that is 5.2 lower; (ii) play 0.62 fewer years in the NFL; (iii) play 0.65 fewer years as a starter; and (iv) be selected 0.12 fewer times as an all-pro.

The estimates similarly revealed that players who entered the league after 1989 were likely to earn a CARAV that is 4.7 higher over the course of their NFL career. Unsurprisingly, a player's draft position was a good proxy for talent, as DRFT was significant at the $1 \%$ level across all specifications. Weight was only statistically significant for YRPS. There was weak and conflicting evidence pertaining to the predictive value of a player's position. Due to the fact that not all position categories are included in the analysis, the results 


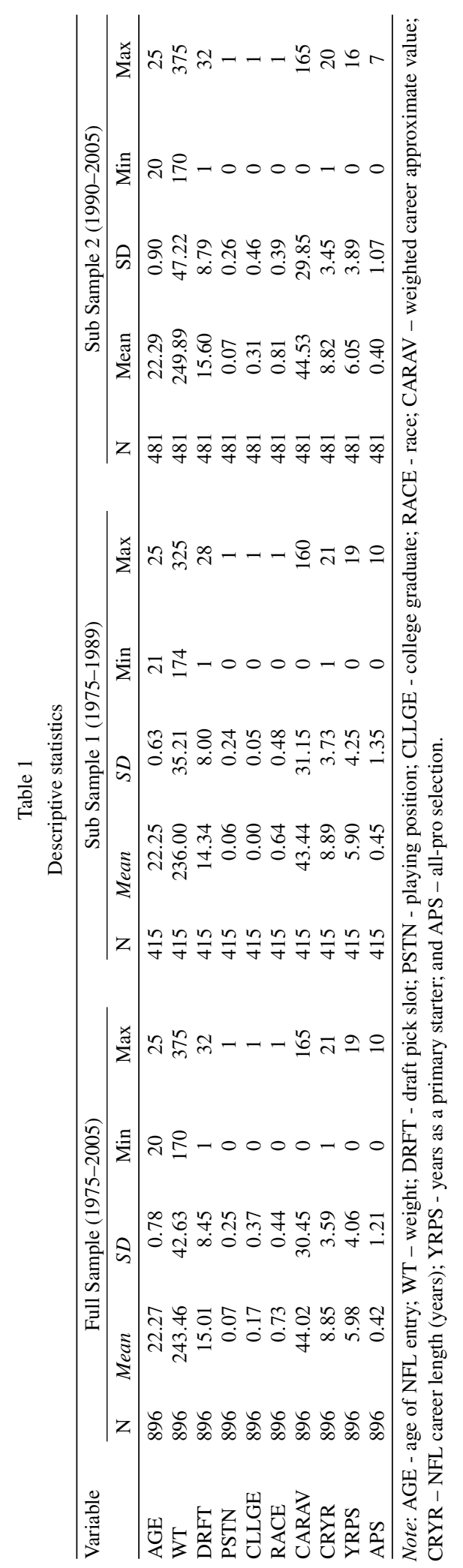


Table 2

Censored normal regression results

\begin{tabular}{|c|c|c|c|c|c|c|c|c|}
\hline Variable & CARAV & & CRYR & & YRPS & & APS & \\
\hline$\overline{\mathrm{AGE}}$ & $-5.179^{* *}$ & $(1.452)$ & $-0.617^{* *}$ & $(0.175)$ & $-0.652^{* *}$ & $(0.192)$ & $-0.120^{*}$ & $(0.054)$ \\
\hline WT & 0.024 & $(0.025)$ & 0.004 & $(0.003)$ & $0.008^{*}$ & $(0.003)$ & 0.001 & $(0.001)$ \\
\hline DRAFT & $-0.936^{* *}$ & $(0.135)$ & $-0.070^{* *}$ & $(0.015)$ & $-0.113^{* *}$ & $(0.017)$ & $-0.026^{* *}$ & (0.006) \\
\hline PSTN & 9.261 & $(5.986)$ & $1.284^{*}$ & (0.657) & -0.222 & (0.708) & -0.264 & $(0.162)$ \\
\hline CLLGE & -0.890 & (3.682) & -0.092 & $(0.431)$ & -0.132 & $(0.474)$ & 0.186 & $(0.145)$ \\
\hline RACE & 3.466 & $(2.580)$ & 0.005 & (0.337) & -0.233 & $(0.370)$ & -0.041 & (0.118) \\
\hline RULECHNG & $4.720^{*}$ & (2.443) & 0.363 & $(0.291)$ & $0.671^{*}$ & $(0.328)$ & 0.084 & $(0.093)$ \\
\hline Constant & 163.654 & & 22.643 & (3.993) & 20.261 & (4.366) & 3.40 & (1.269) \\
\hline Pseudo $\mathrm{R}^{2}$ & 0.01 & & 0.01 & & 0.01 & & 0.02 & \\
\hline
\end{tabular}

Note: Robust standard errors in parentheses. ${ }^{*}$ and ${ }^{* *}$ denote significance at 5 and $1 \%$ levels, respectively.

are limited and cannot be generalized as applying to the degree of association between age and career success across the player's different positions. It is also found no evidence that race predicts NFL career success. Likewise, the completion of college does not result in better on-field outcomes.

\section{Conclusion}

I found evidence that the younger a player is when he first enters the NFL labor market; the more successful he is likely to be. The results of this study also point to NFL teams making prudent draft-day decisions. The precocity-related findings cast doubt on the long-term on-field necessity (and efficacy) of the NFL's age rule, while acknowledging the inability to determine the dominant driver of the results due to the fact that there is no perfect proxy for unobserved variables such as intrinsic talent and human capital accumulation. The results of this study are uniquely germane to the NFL. Rules in MLB, NHL, NASCAR, professional tennis, professional golf, and professional boxing differ markedly. With precocity and NFL career success intertwined, it is expected that perhaps a more nuanced and individualized consideration of a prospective player's draft eligibility would be prudent given the dearth of evidence pointing to any on-field efficacy of the NFL's current age eligibility rule.

\section{Acknowledgments}

I would like to thank Logan Moore and James Rezucha for research assistance. I also would like to thank two anonymous reviewers for helpful comments.

\section{References}

Acemoglu, D. 1996. A microfoundation for social increasing returns in human capital accumulation. Quarterly Journal of Economics. 111, 779-804.

Böheim, R., Lackner, M. 2012. Returns to education in professional football. Economics Letters, 114, 326-328.

Edelman, M., \& Wacker, J.A. 2010. Collectively bargained age/education requirements: A source of antitrust risk for sports club-owners or labor risk for players unions? Penn State Law Review, 115, 341-376.

Fried, H.O., \& Tauer, L.W. 2011. The impact of age on the ability to perform under pressure: Golfers on the PGA Tour. Journal of Productivity Analysis, 35, 75-84.

Goff, B.L., \& Wisley, T.O. 2006. Is there a managerial life cycle? Evidence from the NFL. Managerial \& Decision Economics, 27, 563-572.

Helsen, W.F., Hodges, N.J., Van Winckel, J., \& Starkes, J.L. 2000. The roles of talent, physical precocity and practice in the development of soccer expertise. Journal of Sports Sciences, 18, 727-736.

Hendricks, W., Debrock, L., \& Koenker, R. 2003. Uncertainty, hiring, and subsequent performance: The NFL draft. Journal of Labor Economics, 21, 857-886.

Kahn, L.M. 2000. The sports business as a labor market laboratory. Journal of Economic Perspectives, 14, 75-94.

McCann, M.A., \& Rosen, J.S. 2006. Legality of age restrictions in the NBA and the NFL. Case Western Reserve Law Review, 56, 1-38.

Rodenberg, R.M., \& Kim, J.W. 2012. Testing the on-court efficacy of the NBA's age eligibility rule. Journal of Quantitative Analysis in Sports, 8, 1-21.

Rosen, S. 1983. Specialization and human capital. Journal of Labor Economics, 1, 43-49.

Rosen, S., \& Sanderson, A. 2001. Labor markets in professional sports. The Economic Journal, 111, 47-68.

Schulz, R., \& Curnow, C. 1988. Peak performance and age among superathletes: Track and field, swimming, baseball, tennis, and golf. Journal of Gerontology, 43, 113-120. 
Sowell, C.B., \& Mounts, W.S. 2005. Ability, age, and performance: Conclusion from the Ironman Triathlon World Championships. Journal of Sports Economics, 6, 78-97.

Stair, A., Day, A., Mizak, D., \& Neral, J. 2008. The factors affecting team performance in the NFL: Does off-field conduct matter? Economics Bulletin, 26, 1-9.
Staw, B.M., \& Hoang, H. 1995. Sunk costs in the NBA: Why draft order affects playing time and survival in professional basketball. Administrative Science Quarterly, 40, 474-494. 